\title{
Imaging Features of Cervical Spinal Motion Segment Lesions before and after Surgery: A Case Report
}

\author{
Vladimir A. Sorovikov, MD, PhD, ScD; Pavel V. Seliverstov, MD, PhD, ScD* \\ Irkutsk Scientific Center of Surgery and Traumatology \\ Irkutsk, Russia
}

\begin{abstract}
Spinal injuries remain a serious modern health problem that leads to a high level of disability and prehospital mortality. This clinical case of cervical fracture-dislocation demonstrates the diagnostic signs and the surgical approach. (International Journal of Biomedicine. 2020;10(4):430-432.)
\end{abstract}

Key Words: spinal injury $\bullet$ spinal cord injury $\bullet$ radiology $\bullet$ surgical treatment

\section{Introduction}

According to a number of authors, spinal injuries amount to $1.0 \%-8.0 \%$ of closed trauma and $5.0 \%-20.0 \%$ of total musculoskeletal lesions. Spinal and spinal cord injuries demonstrate an extremely increasing trend in frequency over the past 100 years. In Russia, 10,000 cases are reported annually. ${ }^{(1-3)}$ Spinal and spinal cord injuries are the third leading trauma localization despite all the preventative measures (safe working conditions, vehicle security, etc.). Cervical spine involvement was found in $12.0 \%$ of spinal injuries. When the spinal cord is affected, fatality rates in cervical injuries range from $75.0 \%$ to $80.0 \% .^{(4-6)}$

Acute spinal and spinal cord trauma range from 2.0\% to $3.0 \%$ among all neurosurgical patients; frequently $(40 \%-$ $60 \%$ ) they occur in combination with other bodily damage. . $^{(1,4)}$ Concomitant spinal and spinal cord injuries constituted nearly $75.0 \%$ of these patients; in these cases, mortality is 4 times higher than in patients with an isolated injury. People suffering these injuries are predominantly males (the sex ratio is 3 males to 1 female) of working age ( $80 \%)$. The most common cause of spinal and spinal cord injuries is car accidents $(27 \%-43 \%)$. ${ }^{(6,7)}$

The mortality generally depends on the severity of the spinal cord injury: $37.0 \%$ of injured persons die at the

*Corresponding author: Pavel V. Seliverstov, $M D, P h D, S c D$. Department of Radiology and Minimally Invasive Surgery, Irkutsk Scientific Center of Surgery and Traumatology. Irkutsk, Russia. E-mail:pavv2001@gmail.com prehospital stage. The disability ranges from $50.0 \%$ to $95.0 \%$, sometimes amounting to $100 \%$. $^{(3,8)}$

Early full detection of the pathomorphological changes in spinal lesions predetermines an effective treatment based on the pathogenetic approach. Developments in radiology and new surgical techniques point to the need for deep knowledge of spinal anatomy and biomechanics. An adequate interpretation of radiological spinal anatomy, both normal and in cases of lesions, is a topical medical issue. ${ }^{(9)}$

From the point of view of anatomy and biomechanics, facet joints and intervertebral disks are part of an entity called the spinal motion segment, the three-joint complex (the functional spinal unit (FSU)). Every vertebra belongs to 2 spinal motion segments as an upper part for the lower segment and a lower part for the upper one. Every underlying vertebra is a «transmission» for the overlying one. Nucleo-articular axes allow vertebrae to perform difficult movement as a result of the addition of simple movements around 3 mutually perpendicular axes (vertical, sagittal, and frontal). ${ }^{(2,10)}$

Each motion segment has an instantaneous axis of rotation (IAR), which is a dynamic point about which the FSU rotates and is dependent upon spinal alignment and forces acting on the spine. There are 12 potential movements about the IAR due to rotation around the three axes (x,y, and $\mathrm{z}$ ) that pass through the center of rotation. ${ }^{(11)}$

The treatment of spinal and spinal cord lesions is a severe problem of modern neurosurgery. In most developing countries, there is no contemporary system of urgent, highly specialized medical assistance for these patients. ${ }^{(4)}$ First, an orthopedic 
aspect (a restoration of bearing and protective functions of the spine) should be determined; second, a neurosurgical aspect (a spinal cord restoration). Full-fledged equipment of hospitals with diagnostic machines and with modern implantable metal constructions and adequate funding is essential.

\section{Case Presentation}

A 34-year-old white man presented to the neurosurgery department of Irkutsk Scientific Center of Surgery and Traumatology with a complaint of neck pain and reduced cervical range of motion, left hand pain (the lateral surface of the shoulder, elbow joint, and forearm), and numbness in 4-5 fingers.

Anamnesis: a victim of a car accident, this patient felt acute neck pain, reduced cervical range of motion, and pain and weakness in the left hand. He was taken to the fracture clinic where he was diagnosed with a closed cervical injury, C5 fracture-dislocation, and left side radiculoneuritis in C7. The patient was transferred to the neurosurgical department of Irkutsk Scientific Center of Surgery and Traumatology for special treatment.

The patient was fully conscious and hemodynamically stable. Neurological status: the pupils are equal in size, the reaction to light is brisk, and the amount of eye movement is full. The nasolabial folds are equal, the tongue is at the middle line, the pharyngeal reflex is present, and phonation is good. The tendon reflexes on the arms are brisk, ulnar and radiocarpal reflexes are weak, moderate hypoesthesia in the left lateral forearm surface and in 4-5 fingers. The strength of the left wrist is reduced to 2 points. Status localis: painful palpation in processus spinosus of C5-C7, a muscular tonic syndrome.

The cervical spine X-ray showed (Fig.1) a loss of normal lordosis with a kyphosis of the lower cervical spine; sloped anterior superior part of C5 vertebral body, which is displaced anteriorly for $0.3 \mathrm{~cm}$. There was an oblique radiolucent line in the right arcus of $\mathrm{C} 5$ without fragment dislocation. These radiological signs were visualized: subchondral endplates osteosclerosis, formation of osteophytes, a decrease in the height of the intervertebral discs in a caudal direction, especially in $\mathrm{C} 5-\mathrm{C} 7$; elongation and sharpening of processus uncinatus. The axis is inclined to the right side without vertebral body rotation with a turn of the head.

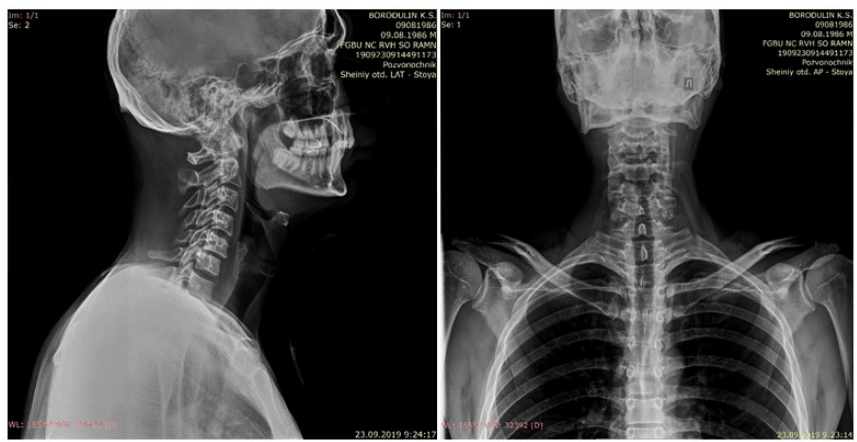

Fig. 1. Cervical spine X-ray. Anterior C5 subluxation. C5 compression fracture (A1). Fracture of the right $C 5$ arcus. Cervical osteochondrosis, stage III. Uncovertebral arthrosis. Spondylosis, grade II.
A clinical diagnosis was determined: Closed spinal and spinal cord injury. C5 fracture-dislocation, interlocking dislocation of the left articular process in C5-C6, left side radiculoneuritis in $\mathrm{C} 7$. Pain and muscular tonic syndrome.

A surgical procedure was performed under endotracheal anesthesia, with the patient lying on his back and with a small head rotation to the right. After disinfection of the surgical field, the surgeons performed a skin incision and used the layer left parapharyngeal access to the anterior surface of the $\mathrm{C} 5-\mathrm{C} 7$ spinal motion segment. The rupture of the annulus fibrosus and pathological anterior dislocation of the C5 body (left side) were observed. There was pathological mobility during palpation of this segment. The surgeons dissected the annulus fibrous and removed the matter of the disc up to the posterior part of the annulus fibrosus with its tear and herniation in the vertebral canal. The $\mathrm{C} 5$ dislocation was reduced with a retractor, a ceramic cage-implant was fixed in moderate axis traction of cervical vertebrae. Thus, the spinal motion segment was stable. Intraoperative X-ray, hemostasis, and wound closure layer-by-layer were performed. After surgery outcomes are presented in X-ray and MSCT (Fig.2 and 3).
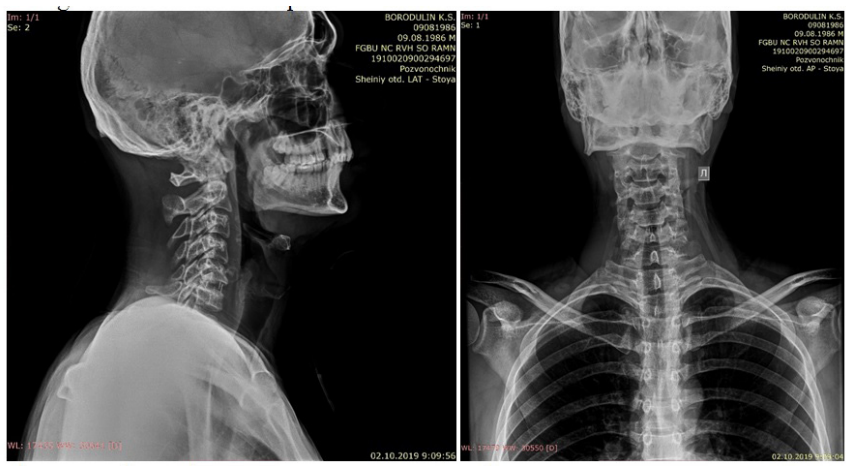

Fig. 2. Cervical spine X-ray. After surgery. Cage-implant at the C5-C7 level. The C5 body is wedge-shape, $1.3 \times 1.6 \mathrm{~cm}$. Anterior superior parts of the C5 body are sloped; there are the osteophytes. The subluxation has been reduced. The loss of normal lordosis. The decrease of the intervertebral discs' height in a caudal direction. The axis is satisfactory.

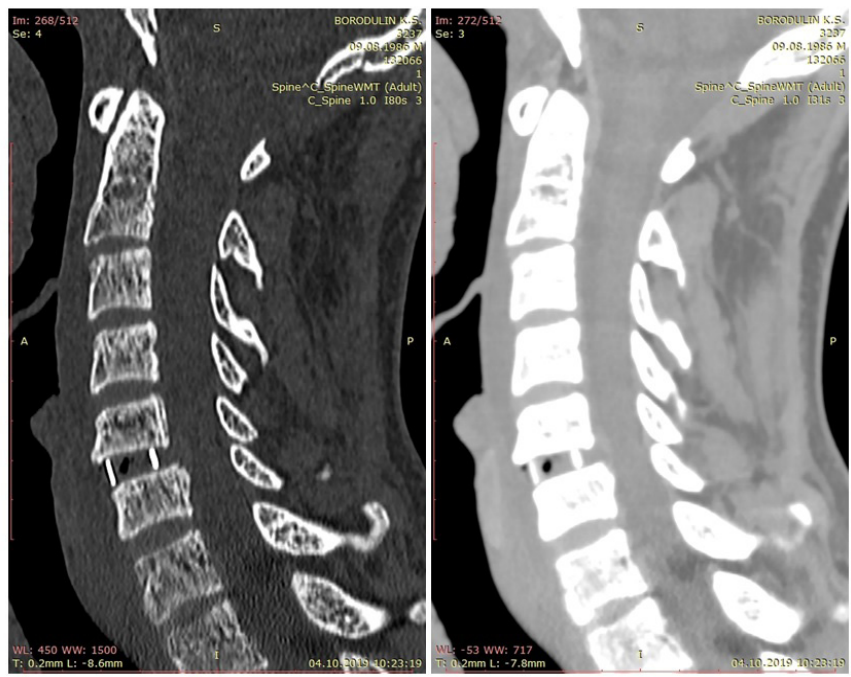

Fig. 3. MSCT. After surgery. 
During the postoperative period, the patient was in a satisfactory state; he was active with cervical orthosis the following day. Neurological status: the pain syndrome regressed, the sensitivity in the left forearm and wrist appeared. The strength of the left wrist was 4 points. The patient was discharged from the hospital in a satisfactory state on the tenth postoperative day. The wound healing was primary.

Control check-up in 6 months (Fig.4): There were no complaints. The patient got down to work in 2 months after he was discharged from the hospital. Neurological status: there were no focal symptoms. Cervical motion to the left was slightly restricted. Palpation of processes spinosus was painless. The tendon reflexes on the arms were brisk, equal. The patient has been managed in accordance with clinical recommendations and protocols at the place of residence.

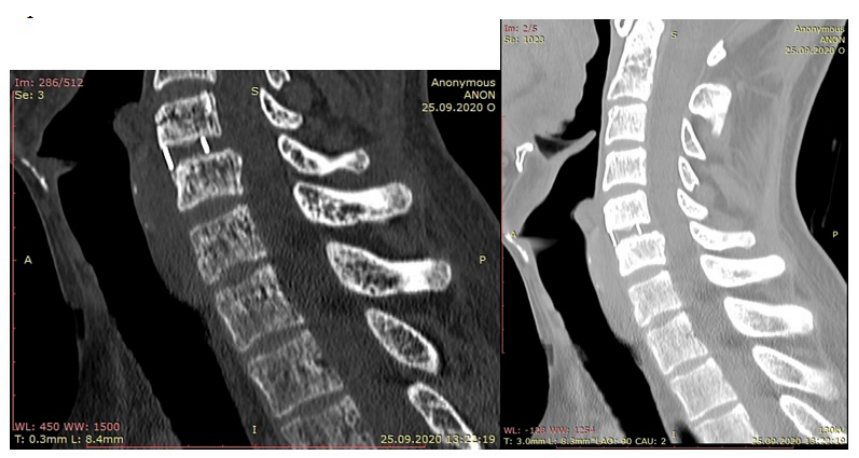

Fig. 4. Control MSCT in 6 months after surgery. The cageimplant is present at the C5-C6 level. Consolidated fracture of left upper articular process of C6. Ante-spondylolisthesis C5, grade 1. Retro-spondylolisthesis C6, grade 1. Spondylosis at the C6 level with local stenosis of vertebral canal. Cervical osteochondrosis, stage II.

In conclusion, the patients with cervical fracturedislocation mostly need a surgical correction. The aims are restoration of the anatomical integrity of the spinal motion segment and resumption of the intact spinal cord. The cage-implant provides anatomical spinal integrity, vertebromedullary conflict prevention, and the reliable stabilization of the injured spine.

\section{Competing Interests}

The authors declare that they have no competing interests.

\section{References}

1. Bersnev VP, Davydov EA, Kondakov EN. [Surgery of spine spinal cord and peripheral nerves]. Saint-Petersburg, 1998. [In Russian].

2. Nechaev VI. Locomotor morphology of spine. [Theory and practice]. Smolensk: Smjadyn'; 2005. [In Russian].

3. Ul'rih EV, Mushkin AJu. [Vertebrology in terms, figures, images]. Saint-Petersburg: ELBI-SPb; 2002. [In Russian].

4. Babichenko EI, Belov VG. [Spinal stabilization in acute spinal and spinal cord injury. Surgery of spine and spinal cord]. Novokuznetsk; 1995:25-31. [In Russian].

5. Chan CW, Eng JJ, Tator $\mathrm{CH}$, Krassioukov A; Spinal Cord Injury Research Evidence Team. Epidemiology of sport-related spinal cord injuries: A systematic review. J Spinal Cord Med. 2016 May;39(3):255-64. doi: 10.1080/10790268.2016.1138601.

6. Mirzaeva L, Gilhus NE, Lobzin S, Rekand T. Incidence of adult traumatic spinal cord injury in Saint Petersburg, Russia. Spinal Cord. 2019 Aug;57(8):692-699. doi: 10.1038/s41393019-0266-4.

7. Jarikov AV, Perl'mutter OA, Fraerman AP, Bojarshinov AA, Sosnin AG, Gun'kin IV, Tihomirov SE. [Complications and faults of surgical treatment of thoracic and lumbar lesions]. Amur Medical Journal. 2019;27(3):65-74. [Article in Russian].

8. Ramih EA. [Evolution of spinal lesion surgery in complex of rehabilitation. Novosibirk scientific research institute of surgery and orthopedics]. Spinal Surgery.2007;(2):77-95. [Article in Russian].

9. Vasilyev AYu, Vit'ko N.K. [Computed tomography in diagnosis of degenerative spinal changes]. Moscow: Izdatel'skij dom Vidar. 2000. [In Russian].

10. Inoue N, Orias AAE, Segami K. Biomechanics of the Lumbar Facet Joint. Spine Surg Relat Res. 2019 Apr 26;4(1):17. doi: 10.22603/ssrr.2019-0017.

11. Iorio JA, Jakoi AM, Singla A. Biomechanics of Degenerative Spinal Disorders. Asian Spine J. 2016 Apr;10(2):377-84. doi: 10.4184/asj.2016.10.2.377. 